pÿEthics in the supervisory relationship : supervisors and pÿdoctoral students dilemmas in the natural and behavioural sciences

\title{
Löfström, Erika
}

2017

pÿLöfström , E \& Pyhältö , K 2017 , ' Ethics in the supervisory relationship : supervisors and pÿdoctoral students dilemmas in the natural and behavioural sciences ', Studies in Higher Education, vol. 42 , no. 2 , pp. 232-247 . https://doi.org/10.1080/03075079.2015.1045475

http://hdl.handle.net/10138/232985

https://doi.org/10.1080/03075079.2015.1045475

acceptedVersion

Downloaded from Helda, University of Helsinki institutional repository.

This is an electronic reprint of the original article.

This reprint may differ from the original in pagination and typographic detail.

Please cite the original version. 


\section{ALMOST FINAL VERSION}

To cite, please refer to:

Löfström, E. \& Pyhältö, K. (2015). Ethics in the supervisory relationship: supervisors' and doctoral students' dilemmas in the natural and behavioural sciences. Studies in Higher Education, 42(4), $232-$ 247. DOI: $10.1080 / 03075079.2015 .1045475$.

Ethics in the supervisory relationship: Supervisors' and doctoral students' dilemmas in the natural and behavioural sciences

Erika Löfström \& Kirsi Pyhältö

\section{Introduction}

Supervision is a key component of doctoral studies. It has been shown that supervision contributes to degree completion, length-of-time to candidacy, doctoral student well-being and satisfaction with the overall doctoral experience, as well as to competencies developed while studying (Meyer, Shanahan, and Laugksch 2005; Case 2008; Pyhältö, Stubb, and Tuomainen 2011). Simultaneously, there is evidence that students who collaborate closely with faculty on research projects are also the students most frequently exposed to unethical behaviour (Anderson, Louis, and Earle 1994). On the other hand, True, Alexander, and Richman (2011) have reported that ethical misconduct was most prevalent among research workers who were not well integrated into their academic communities. Although formal ethics training is thought to be important for instilling knowledge of ethical norms and standards (e.g. Zucchero 2008; Burr and King 2012), students learn ethical guidelines 
and codes of conduct from their supervisors and senior colleagues as they engage in research (Alfredo and Hart 2011; Gray and Jordan 2012). The supervisory relationship is thus a crucial means of learning appropriate practices and codes of conduct. Yet we know little about whether or not doctoral supervisors and doctoral students identify similar ethical issues embedded in doctoral supervision. The present investigation focusses on analysing the fit between supervisors' and doctoral students' perceptions of ethic al issues in the natural and behavioural sciences.

\section{Supervision as an arena for ethical problem solving}

Doctoral supervision provides a potential arena for learning to identify ethical problems and for solving them in an ethically sustainable manner. Some of the issues are internal to the research process, that is, they pertain to how researchers treat research participants, obtain or negotiate informed consent, ensuring the anonymity of participants and maintain the confidentiality of data. However, ethical issues can also involve relationships with colleagues, financing agencies and other stakeholders, or recognition of authorship. Ethical issues pertaining to these 'external' aspects form the primary focus of this article. Prior research has identified a variety of ethical problems embedded in supervision, such as incompetent and inadequate supervision, supervision abandonment, intrusion of supervisor views, abusive and exploitative supervision, dual relationships, encouragement to commit fraud, and authorship issues (Goodyear, Crego and Johnston 1992; Löfström and Pyhältö 2012, 2014; Mahmud and Bretag 2013). However, not all the challenges faced in supervisory relationships or doctoral studies are ethical in nature. They may be, for instance, primarily structural issue or issues of differing ontological and epistemological viewpoints. Therefore, well-grounded criteria for identifying ethical issues 
in the context of doctoral education are needed. Furthermore, there are many ways to approach dilemmas both in ethically sustainable ways as well as in non-sustainable ways.

The present study draws on a model of ethical principles, including (1) respect for autonomy, (2) avoiding harm (non-maleficence), (3) benefiting others (beneficence), (4) being just (justice), and (5) being faithful (fidelity) ( Kitchener 1985; 2000). This model was initially developed for counselling and advising in a university context, which are activities with much in common with doctoral supervision. The components of the model underpin many ethical codes and guidelines (e.g. European Commission 2007; Finnish Advisory Board on Research Integrity 2012; see also the analysis of European ethical guidelines by Godecharle, Nemery, and Dierickx 2013) and provide in that sense a largely agreed-upon set of principles of ethics and integrity. We draw on this model in order to identify and analyse the ethical challenges in our data.

Respect for autonomy refers to the right to self-determination, the right to privacy and the individual's right to make decisions concerning their own life. Lack of autonomy has been reported as causing problems, including cynicism and feelings of inadequacy in early career academics (Sutherland 2013; Vekkaila et al. 2012). Non-maleficence entails the necessity of avoiding psychological, physical or social harm. A number of doctoral students have, however, been reported to experience significant amounts of distress during their studies (Anderson and Swazey 1998; Hyun, Quinn, Madon, and Lustig 2007; Kurtz-Costes, Helmke, and Ülkü-Steiner 2006) and sometimes discrimination based on their ethnic backgrounds or gender (Truong 2010). Beneficence entails making a positive contribution to another's welfare and personal growth; it can be compromised by not providing support or help to others who are needy. In doctoral studies the lack of supervisory support (Löfström and Pyhältö 2014) and experiences of being isolated and considerations of withdrawal from 
doctoral studies (Pyhältö, Stubb, and Lonka 2009) could be consequences of breaches of beneficence. Justice includes fairness, impartiality, reciprocity and equality. In social and professional contexts obligations come with relationships of unequal power distribution, such as between professionals and their clients (Kitchener 1985) or, in our case, between a supervisor and a student. Fidelity refers to keeping promises, being loyal, showing truthfulness and respect for others. Without fidelity, forming and sustaining relationships is impossible.

\section{The dynamics of the supervisory relationship}

The dynamics of supervisory relationships that contribute to the nature of ethical problems faced, including ways in which problems are solved, can be explored in terms of supervisory relationship fit. The congruence or lack thereof between doctoral students and their working environments has been shown to influence the students' doctoral experience and their completion of the process (Golde 2005; Pyhältö, Vekkaila, and Stubb 2012). Golde (2005), for instance, found that a misfit between doctoral students' goals, expectations and the norms and practices in their scholarly community negatively affected their persistence. Moreover, it has been shown that conflict between institutional and personal values and lack of support are likely to foster academic misconduct (Bruhn 2008).

A perceived misfit between doctoral students and their working environment in terms of problems with supervisors and uncertain career prospects has been shown to contribute to ethical misconduct (Anderson and Louis 1994). In highly competitive institutions, where the focus is on 'weeding out' less successful students from the more successful ones, students may be more prone to adopt counter-norms to academic ideals, such as emphasis on personal gain over the pursuit of knowledge and discovery (ibid., 1994). Perceived fit has 
also been suggested to contribute to the ways in which doctoral students interact with their communities and how they perceive themselves (Sweitzer 2009). Pyhältö, Stubb and Lonka (2009), for example, found that both the definitions of 'scholarly community' and doctoral students' experiences of their membership in scholarly communities varied considerably: approximately one-third of the doctoral students felt isolated from their academic communities or experienced their relationship to the community as somewhat problematic.

Thus, there is a growing body of evidence to suggest that the fit between the doctoral student and his or her learning environment, including the supervisory relationship, indeed matters. However, to our knowledge no previous studies have explored the fit between the ethical issues embedded in supervision as perceived by the doctoral students and the supervisors. Yet there are some indicators that doctoral students and their supervisors do not necessarily share similar perceptions of the issues. For example, doctoral students have been found to emphasise social support, interaction with researchers and adequate funding as key resources for their doctoral studies (Gardner, 2007; Protivnak and Foss 2009), while identifying lack of supervision, destructive friction within the scholarly community and problems in developing expertise as a scholar as core problems (Vekkaila et al., 2012). Supervisors, on the other hand, have emphasised resources, particularly funding, as well as student characteristics, such as motivation, internal locus of control and self-direction, as central ingredients for completing a doctoral degree (Gardner 2009). It has also been suggested that the guidance that supervisors give their doctoral students may not always be the kind of support that the students are seeking. For instance, sometimes the supervisors offered pastoral support when the student was looking for support with project management or vice versa (Deuchar 2008). The findings indicate that supervisors and 
doctoral students may perceive supervisory activities and the challenges involved in these activities differently. Consequently, ethical issues may also be perceived differently.

This study focussed on exploring students' and supervisors' perceptions of ethical issues in doctoral supervision. The ethical issues in supervision identified from the perspectives of students and supervisors have been described in Löfström and Pyhältö $(2012,2014)$. Some of the issues may be breaches of ethics or integrity, i.e. ethical problems. However, often they are issues that are tricky or challenging to navigate, but without a clear-cut integrity or ethics breach. The present investigation compares the nature of those ethical questions and analyses the fit/misfit between the perceptions of doctoral students and those of supervisors. The following research questions were addressed:

(1) To what extent do doctoral students and their supervisors experience similar or different ethical challenges in the supervisory relationship?

(2) Do the natural and behavioural sciences differ from each other in terms of fit between the students' and supervisors' perceptions of ethical problems?

\section{Context: Doctoral education in the natural and behavioural sciences}

In Finland doctoral studies are heavily centred on conducting research, which is estimated to be 75 per cent of the total work for a doctoral degree and usually begins at the start of the doctoral studies. Doctoral studies are estimated to equal four years of full-time study. No extensive course work is required before undertaking doctoral research. Subject and methodological studies amount to 40-60 ECTS credits (1 credit in the European Credit Transfer System equals approximately 27 hours of study), depending on the discipline. 
In the natural sciences at the target university the majority $(81 \%)$ of doctoral candidates pursue article-based dissertations. These consist of three to five internationally refereed journal articles co-authored with the supervisor and other senior researchers including a summary tying together the individual articles and synthesising methodological aspects and findings (Pyhältö, Stubb, and Tuomainen 2011). Thus, doctoral candidates in the natural sciences often work intensively in relatively strong research communities, which include several doctoral students and academics at various stages of their careers who collectively focus on solving shared or related research problems within a project.

Likewise, in the behavioural sciences, the article compilation with a synthesising summary has become the dominant form (66\%) of dissertation in recent years (Pyhältö, Stubb, and Tuomainen 2011). The article compilation, however, is more prevalent in psychology than in education, where the monograph is still the dominant form of dissertation. Doctoral students who write monographs often engage in seminars, and supervision is based on supervisor-student dyads rather than on team work in research labs. Doctoral supervision is usually based on apprenticeship, both in the research teams and in the supervisor-student dyads.

Doctoral education is publicly funded and free for the students, who nevertheless pay for their costs of living, often covered by personal grants, project funding or salary from work outside academia (Pyhältö, Stubb and Tuomainen 2011). A description of doctoral education in Finland can be found in the International Postgraduate Student Mirror (2006). 


\section{Method}

\section{Participants}

Data were collected from doctoral students and supervisors $(\mathrm{N}=42)$ in two research communities in the natural and behavioural sciences at a research-intensive university in Finland. Both are well-established research communities. Altogether 14 supervisors and 28 doctoral students were interviewed. The doctoral students consisted of 21 students in the behavioural sciences ( 17 females and 4 males) and 7 students in the natural sciences ( 2 females and 5 males). All the students had master's degrees, and they were in different phases of the doctoral process. According to the students' own estimates, 11 were at the beginning of the doctoral process, 5 were in the middle and 9 were in the last phases. Three participants were recent graduates. Nineteen of the participants were or had been full-time students, and 8 were pursuing their doctoral studies part time. Six of the students wrote a monograph-type dissertation, 16 wrote an article-based dissertation, and 6 students were undecided about the dissertation form.

Eight supervisors from the natural sciences and six supervisors from the behavioural sciences were interviewed (3 females, 11 males). All had PhD degrees and were professors or adjunct professors, and most had several doctoral students under their supervision.

Doctoral student and supervisor interviews

The doctoral supervisor interviews included questions on three general themes: (1) the doctoral process, (2) supervision practices and (3) oneself as a supervisor. The interview instrument was intended to obtain a broad view of the supervisors' work and especially of 
the different aspects of supervising doctoral students. Altogether, the semi-structured interview contained eighteen questions on different aspects of the supervisors' work and six background questions on the participants' working history, years of supervising and current position. All questions and instructions were validated by the members of the research group before the interviews.

The doctoral students were recruited from among the participants in the research seminars in the two academic communities in which supervisors were interviewed. Project researchers informed prospective participants about the aims, procedures and ethical aspects of the research. Participants were also given an opportunity to ask questions about the project. Thereafter, an invitation accompanied with information about the research project was sent to all doctoral supervisors and doctoral students within the communities at the time. The doctoral student interviews were designed to investigate three major themes: 1) the doctoral students' experiences of the dissertation process, 2) supervision and 3) perception of self as doctoral student (cf. Stubb 2012). At the beginning of the interviews the students were asked a few background questions about their discipline or subject, the time spent on their dissertations/studies, the phase of the process at which they were at the time and the estimated or actual time of graduation, the form of the dissertation and whether they were studying full time or part time. The interviews focussed both on retrospective experiences during the $\mathrm{PhD}$ process and on the present situation.

Each interview lasted between approximately 60 and 90 minutes. All the participants were interviewed on a voluntary basis. The interviews were recorded and transcribed verbatim. Owing to the sensitive nature of some of the data, we have not provided background information for the interview quotations. We have neutralised references to the interviewees' gender and the gender of people mentioned in order to protect the 
research participants and third parties. We have included excerpts from the data to highlight student and supervisor views, and, in order to protect the anonymity of the participants, we have not paired quotations on the same event from a supervisor-student pair.

Analysis

The data were analysed by theory-driven content analysis (cf. Marshall and Rossman 1995). Kitchener's $(1985 ; 2000)$ five ethical principles were applied as a framework for identifying ethical issues in the data. The analysis focussed on overt ethical issues either explicitly mentioned in the interviews or suggested as ethical issues by the interviewee, and on latent ethical themes evolving from the interviews (cf. Braun and Clarke 2006). The unit of analysis was a whole thought or theme. All units were subjected to the question 'Which ethical principle is compromised and how?' to ensure that we were not dealing with pseudo-ethical issues, but included only truly ethical issues in the analysis.

The process of analysing the data was iterative in nature. We ended up with 102 identified units of ethical issues in the doctoral student data and 55 in the supervisor data. We made condensed descriptions of each unit of analysis. These descriptions helped us to identify common themes and form sub-categories. The same participant could have more than one ethical issue in the same category, but generally this was not the case. The analysis was conducted by the first author, but between the iterations, the second author commented on the analysis. Interpretation was negotiated if the two authors held different views. For instance, the authors discussed whether to include issues attributable to the structures of the doctoral programmes, as these would be issues that might influence how fair the students experienced their supervision to be. In this case we decided to exclude 
structural issues in general, but we retained two units of analysis where we felt that the structural aspects threatened the principle of beneficence. Another discussion pertained to the identification of the role of students' life situations in their experiences of problems in their PhD process. We included only those units wherein, in our interpretation, the lack of the supervisor's compassion worked against the principle of beneficence.

\section{Results}

The results indicated that the doctoral students and the supervisors encountered, in general, rather similar kinds of ethical dilemmas. All five ethical principles appeared in both the student and the supervisor data (Table 1). The dilemmas varied from exploitation to problems in keeping supervision commitments. However, differences between the students and supervisors' perceptions were also identified. Non-maleficence-related ethical issues were emphasised by the supervisors, whereas beneficence, fidelity and justice-related ethical issues were emphasised by the doctoral students. Supervisors and doctoral students sometimes reflected on the ethical issues from different perspectives.

Table 1: Ethical principles at stake in supervision from the students' and from the supervisors' perspectives.

\begin{tabular}{lll} 
& $\begin{array}{l}\text { Supervisors } \\
f(\%)\end{array}$ & $\begin{array}{l}\text { Doctoral students } \\
f(\%)\end{array}$ \\
\hline Non-maleficence & $29(53)$ & $17(17)$ \\
Beneficence & $12(21)$ & $35(34)$ \\
Autonomy & $5(9)$ & $12(12)$ \\
Fidelity & $7(13)$ & $26(25)$ \\
Justice & $2(4)$ & $12(12)$ \\
\hline Total & $55(100)$ & $102(100)$
\end{tabular}


More than half of the ethical issues identified in the supervisory data were related to non-maleficence, including exploitation and abuse. Simultaneously, less than a fifth of the episodes in the student data entailed problems of avoiding harm. Within this category the doctoral students called attention to exploitation, abuse and misappropriation. One student described experiences of exploitation in the following way:

Sometimes I've had difficulties concentrating on my own research, not to mention writing a dissertation, because I've had to assist in other people's projects.... It is irritating when professors ask 'When will your dissertation be ready?' and you have just been sweating blood and you are like, 'I've had a bit of things to do!' But when you are in a research group, you do the work, for instance, if someone is on parental leave, then the measurements still need to be made and someone has to take care of that. It takes time away from your own research.

In the excerpt the student described pressures from supervisors and team members, and recognises the necessity of individuals helping each other. Simultaneously, the interview revealed that the student's experience is that of over-working and exploitation, which can be understood as issues of harm.

The supervisors emphasised exploitation and abuse as well as dual relationships, i.e. emotionally- or psychologically-confounded relationships (intimate relationship, childparent-like relationship and patient-therapist-like relationship) as a potential source of harm (Table 2). When supervisors mentioned dual relationships, they mostly related back to a time when they themselves were PhD students or described situations in which students placed unwarranted demands on them as supervisors. As one supervisor put it: 
Some students expect their mentor and supervisor to be a job-finding office. And that's when I say, hell, no!

Here the supervisor recognised that there is a misfit between the supervisor's and the student's expectations, and found him or herself in a situation where it was necessary to clearly define one's own role so as not to be harmed, that is, feel exploited.

One third of the ethical issues in the student data and one fifth of the issues in the supervisor data pertained to the principle of beneficence. In both supervisor and student data we identified ethical issues in supervisors' competence and in the lack of adequacy of the support provided to the students. The striking difference, however, was that in the students' data, we identified 23 distinct suggestions for student well-being that was at stake and six suggestions about the lack of a collective culture hampering the students' progress (Table 2), yet these issues did not emerge in the supervisor data.

Autonomy issues were raised both among students and supervisors. Whereas supervisors raised concerns over conflicting demands between providing overt direction and allowing students' freedom with regard to choices relating to their PhD research, students were concerned with intrusion of supervisor values and the lack of tolerance for perspectives differing from those prescribed by the supervisor. The following quotations illustrate the dilemma of autonomy from the two perspectives:

We are taught to question things, and that's good. Knowledge is cumulative and the field doesn't develop unless we draw upon others' work and find something to critique. And that's the dilemma. It would be great to be able truly to have a discussion with my supervisor. But it isn't like that. My supervisor will say, 'No, no, no, that's not how it goes!' This is a problem in my opinion. (Student) 
The doctoral student receives, but simultaneously also preserves or develops his or her own perspectives, which at best deviate in interesting ways from the supervisor's ideas. So it is difficult because you never know when you might have pushed an idea too strongly and prevented the doctoral student from developing his or her own idea, or the other way around: when you should have been more forceful and not left it up to the student to decide. (Supervisor)

These excerpts illustrate the two sides of the same coin. On the one hand, the student struggled with developing his or her own 'researcher voice' and felt pressured to adopt the ideas promoted by the supervisor. The student experienced that there are no other options than prescribing to the supervisor's views, which contrasted with the student's sense of autonomy. On the other hand, from the supervisor's perspective, finding a balance between direction and supporting student autonomy may pose a dilemma, the consequences of which the supervisor is well aware of.

A fourth of the ethical issues in the student data and slightly over a tenth in the supervisor data pertained to fidelity. Both groups identified supervision abandonment as an issue:

We have a post-doc in the group who defended before me and started to supervise a doctoral student of mine. I was satisfied because I was short on time; I saw no problem as long as papers and the dissertation would get ready. I have no desire to keep all the students to myself. But for many years nothing happened, and I had to intervene because the student was paid from my project, and I had the ultimate responsibility. (Supervisor) 
Here, the supervisor grappled with the issue of fidelity. In order to assure that the student receives appropriate guidance, the supervisor had assigned supervisory responsibilities to one of the team members with the result that the student was left to his or her own devices. The attempt to keep the supervision promise turned out to breach precisely that promise. The interview illustrates the pressures felt by team leaders and the constant juggling of different choices pertaining to supervision. The excerpt also lifts forth another matter, namely the inefficient use of public funds. Thus, fidelity operates in both directions: keeping the supervision promise towards the student, and using public funds for the purpose they have been allocated for.

Some students reported receiving supervision, but perceived it as inadequate or in some respects lacking in quantity and quality:

In the beginning I did not get any supervision at all for the first two years. My supervisor would just say 'do this' or 'do that'. (Student)

This excerpt emphasises the importance of supervisors being explicit about why they ask students to perform certain tasks and allow for sufficient space for students to reflect on how the tasks they perform contribute to their development as researchers.

Furthermore, the student data suggested that some students suffered from disrespectful treatment (Table 2). However, sometimes even gentle and justified criticism of a student's activities or contributions could be experienced as criticism of oneself as a person. Students, however, also described episodes of having been publicly humiliated, belittled and ignored, and there can be no excuse for the disrespectful treatment of others. 
A smaller number of the issues both in the supervisors' and students' data pertained to justice. The following quotation illustrates one student's experience:

There's a caste system. There is clearly an implicit hierarchy, and if your background is not in [the field], then you are of a lower caste. It is not evident in daily life. It is difficult to explain. But there is fierce competition and favouritism. So how fair is that?

In the excerpt above, the student experienced that hierarchical structures in the research team hampered the fair treatment of individuals. In this case, these hierarchies emerged as the valuing of some disciplines over others. Such hierarchies could be deeply rooted in the faculty, and as such, difficult to pin down, yet likely to influence team work in adverse ways.

Breaches of justice could also take other forms. Students described situations in which their contributions were not recognised in a fair manner and their work had been used to advance the goals of the supervisor in a way that did not seem to be doing justice to the students, who did not receive due credit for their work.

Rarely did supervisors recognise that justice was at stake, but one elaborated in depth on the dilemma of treating students the same versus in a fair way:

What the students want from the supervisor is fair treatment. This is a bit tricky because you might yourself think that you are treating them all equally, but that doesn't automatically mean that you give them all the same jobs and the same amount of work. From my perspective, I can give certain tasks to some students and that much more work. It should be related to their skills and capacity, and that is 
fairness, but they don't see it that way. They want everything to be exactly the same.... That's a problem because you should treat them in a fair way, but true equality where everything is precisely and evenly shared is impossible.

Table 2: The nature of ethical issues embedded in supervision.

\begin{tabular}{llcc}
\hline $\begin{array}{l}\text { Principle at } \\
\text { stake }\end{array}$ & Sub-categories & $\begin{array}{c}\text { Supervisors } \\
\mathrm{f}(\%)\end{array}$ & $\begin{array}{c}\text { Students } \\
\mathrm{f}(\%)\end{array}$ \\
\hline Non- & Exploitation and abuse & $19(35)$ & $12(12)$ \\
maleficence & Misappropriation & - & $5(5)$ \\
& Dual relationships & $10(18)$ & - \\
\hline Beneficence & Well-being & - & $23(22)$ \\
& Lack of a collective culture & - & $6(6)$ \\
& Supervisor competence & $4(7)$ & $4(4)$ \\
& Structural issues & - & $2(2)$ \\
& Boundaries of supervisor role/support & $8(14)$ & - \\
\hline Autonomy & Intrusion of supervisor views & - & $6(6)$ \\
& Narrowness of perspectives & - & $6(6)$ \\
& Conflicting demands & $5(9)$ & - \\
\hline Fidelity & Abandonment & $7(13)$ & $14(13)$ \\
& Inadequate supervision & - & $9(9)$ \\
& Disrespect & - & $3(3)$ \\
\hline Justice & Inequality & $2(4)$ & $9(9)$ \\
& Unfair owner-/authorship & - & $3(3)$ \\
\hline Total & & $55(100)$ & $102(100)$
\end{tabular}

Differences between the domains

Non-maleficence-related issues were emphasised more in the natural sciences than in the behavioural sciences. Beneficence and autonomy-related ethical issues on the other hand were emphasised in the behavioural sciences.

In the natural sciences (Table 3), avoidance of harm boiled down to concerns over exploitation/abuse in both groups. Also, beneficence was perceived to be at stake both among the students and the supervisors, but it took different forms depending on the perspective. Whereas supervisors were concerned and probed the boundaries of their role, 
students experienced threats to their well-being and to a lesser extent a lack of collective culture and supervisor competence. Doctoral students in the natural sciences were not concerned about their autonomy, but they sometimes described supervision abandonment, inadequate supervision (fidelity), and inequity and unfair authorship (justice). The supervisors were relatively unconcerned about these issues. Only supervision abandonment was raised as a concern to some extent.

Table 3: Ethical issues embedded in the natural sciences from students' and supervisors' perspectives.

\begin{tabular}{llcc}
\hline $\begin{array}{l}\text { Principle at } \\
\text { stake }\end{array}$ & Sub-categories & $\begin{array}{c}\text { Supervisors } \\
\mathrm{f}(\%)\end{array}$ & $\begin{array}{c}\text { Students } \\
\mathrm{f}(\%)\end{array}$ \\
\hline Non- & Exploitation and abuse & $13(48)$ & $4(18)$ \\
maleficence & Misappropriation & - & $1(4)$ \\
& Dual relationships & $5(19)$ & - \\
\hline Beneficence & Well-being & - & $3(13)$ \\
& Lack of a collective culture & - & $1(4)$ \\
& Supervisor competence & - & $1(4)$ \\
& Boundaries of supervisor role/support & $5(19)$ & - \\
\hline Autonomy & Conflicting demands & $1(3)$ & - \\
& & & \\
\hline Fidelity & Abandonment & $3(11)$ & $6(26)$ \\
& Inadequate supervision & - & $2(9)$ \\
\hline Justice & Inequity & - & $3(13)$ \\
& Unfair owner-/authorship & - & $2(9)$ \\
\hline Total & & $27(100)$ & $23(100)$
\end{tabular}

In the behavioural sciences, problems in maintaining non-maleficence included concerns over exploitation/abuse and experiences of dual relationships among the supervisors and concerns about exploitation and misappropriation among the students (Table 4). Again, beneficence was reported to be at stake in some episodes described by both the students and the supervisors. However, differences occurred; whereas supervisors were concerned about the boundaries of their role and their competence, students experienced threats to their well-being, a lack of collective culture, lack of supervisor 
competence and issues with the structure of the doctoral programme. In contrast to the students in the natural sciences, the students in the behavioural sciences more often experienced the intrusion of supervisor values and viewpoints, and the narrowness of perspectives threatened their sense of autonomy. The supervisors in turn grappled with conflicting demands. The students in the behavioural sciences encountered supervision abandonment, inadequate supervision and disrespect (fidelity), along with inequity and unfair authorship (justice). The supervisors were relatively unconcerned about these issues. Only supervision abandonment was a concern raised by the supervisors.

Table 4: Ethical issues embedded in the behavioural sciences from students' and supervisors' perspectives.

\begin{tabular}{llcc}
\hline $\begin{array}{l}\text { Principle at } \\
\text { stake }\end{array}$ & Sub-categories & $\begin{array}{c}\text { Supervisors } \\
\mathrm{f}(\%)\end{array}$ & $\begin{array}{c}\text { Students } \\
\mathrm{f}(\%)\end{array}$ \\
\hline Non- & Exploitation and abuse & $6(22)$ & $8(10)$ \\
maleficence & Misappropriation & - & $4(5)$ \\
& Dual relationships & $5(18)$ & - \\
\hline Beneficence & Well-being & - & $20(25)$ \\
& Lack of a collective culture & - & $5(6)$ \\
& Supervisor competence & $4(14)$ & $3(4)$ \\
& Structural issues & - & $2(2)$ \\
& Boundaries of supervisor role/support & $3(11)$ & - \\
\hline Autonomy & Intrusion of supervisor views & - & $6(8)$ \\
& Narrowness of perspectives & - & $6(8)$ \\
& Conflicting demands & $4(14)$ & - \\
\hline Fidelity & Abandonment & $4(14)$ & $8(10)$ \\
& Inadequate supervision & - & $7(9)$ \\
& Disrespect & - & $3(4)$ \\
\hline Justice & Inequity & $2(7)$ & $6(8)$ \\
& Unfair owner-/authorship & - & $1(1)$ \\
\hline Total & & $28(100)$ & $79(100)$
\end{tabular}

\section{Discussion}

The findings indicated that while both supervisors and doctoral students perceived ethical dilemmas pertaining to all five ethical principles, i.e. non-maleficence, beneficence, 
autonomy, fidelity and justice, they generally emphasised different aspects of these principles. A substantial portion of the ethical dilemmas in the data pertained to nonmaleficence, typically exploitation. This implies that supervisors may need to be particularly sensitive to exploitation, because students have been shown to have many uncertainties regarding the appropriateness and boundaries of various aspects of student-faculty interaction, including social, personal and "business" components of the relationship (Holmes, Rupert, Ross and Shapera 1999). Moreover, both supervisors and doctoral students described episodes related to autonomy. For supervisors the balancing act between direction and allowing the student freedom posed an ethical dilemma. Essentially supervisors appeared to grapple with the issue of students having to submit to and overcome dependency in order to be recognised as a full-fledged academic (cf. Lee and Williams 1999). The same struggle may be true for the students as well, however, manifested differently. From the students' perspective, the ethical issues had to do with supervisors limiting their choices regarding their research. The more students gravitate from the periphery of a community of practice towards its centre, the more likely the range of options and perspectives in research are narrowed down (Pallas 2001), and this appears to be true for the doctoral student especially in the behavioural sciences.

There were differences, i.e. a misfit between the ethical problems experienced by doctoral students and their supervisors. While supervisors emphasised dilemmas related to non-maleficence, doctoral students emphasised the dilemmas related to beneficence, fidelity and justice. Also in regard to some of the dilemmas, supervisors and students had different emphases. None of the students, for example, mentioned dual relationships. When supervisors described dual relationships, they pertained either to their own experiences of being doctoral students, or they recognised various role expectations that 
might confuse or stretch the role of academic supervising of doctoral students. On the other hand, the supervisors did not raise concerns over student well-being. One reason for this may be that the supervisors had adopted a more task-orientated approach than the students. Supervision abandonment and inadequate supervision emerged as issues primarily in the student data. Supervisors might feel that they are on the whole doing a decent job supervising doctoral students, and often in large numbers. However, for the individual student, the process is unique, and if at crucial points in the process the supervisor is not available, then the student may feel that the supervision was inadequate. In order to counteract supervision abandonment, it may be important to think of ways to recognise and reward supervision efforts for the collective good of the research community (Löfström and Pyhältö 2014).

Furthermore, the supervisors rarely identified justice as an ethical problem in the supervisory relationship, while this was frequently a concern among the doctoral students. The supervisors recognised that their students are a rather diverse group with different strengths and weaknesses; consequently, supervision interventions need to be tailored. For students, the different kinds of support and opportunities may make it seem as if students are being treated in an unequal way. These findings support previous research on doctoral supervision, which suggests that there are discrepancies between supervisors' and students' views of supervision (Murphy 2004). The fact that supervisors and students tackle different ethical issues suggests that there are aspects in the supervisory relationship and process for which there is no shared understanding. It is difficult to solve any problems, including ethical ones, if the parties have very different understandings of where the core of the issue lies. Discrepancies between supervisors and students perceptions of what is appropriate 
and what is not may open up opportunities for revisiting institutional policies on integrity and doctoral education (cf. Royal, Parrent and Clark 2011).

Different ethical issues were emphasised in the natural sciences as opposed to the behavioural sciences suggesting that the discipline-specific features of doctoral education may help to alleviate some ethical issues while emphasising others. For instance, nonmaleficence-related issues were disproportionately emphasised in the natural sciences, whereas beneficence and autonomy-related ethical issues were emphasised in the behavioural sciences. In the natural sciences the students worked in teams composed of academics focussing on several projects simultaneously. This could blur the boundaries of supervision responsibilities and work distribution and may result in some individuals finding themselves doing excessive work without any primary supervisor to turn to (Löfström and Pyhältö 2014).

Other types of issues were more common in the behavioural sciences. In the dyadic model of supervision doctoral students gravitate towards individual professors, and when students seek supervision from a chosen individual, the commitment of the two parties is specifically sought prior to beginning the supervision (Löfström and Pyhältö 2012). While there is merit in this procedure, it may increase the risk for narrowing the theoretical and methodological perspectives that infringe on a student's autonomy unless the student is sufficiently exposed to various alternative view points. It has been shown that supervisor ethicality and respect for students' research decisions improve the ethical attitudes of students (Gray and Jordan 2012). In this sense the ethical problems that students experience in terms of their autonomy could have detrimental consequences for the integrity of the doctoral process. 
Overall, doctoral students in the behavioural sciences exhibited a wider range of ethical issues in supervision. Anderson and Swazey (1998) identified significant disciplinary differences in doctoral students' experiences of the climate at their institutions. In their study sociology students had significantly more negative views of the community-building aspects of their institution than, for instance, chemistry students. Simultaneously, students of sociology were the most likely to agree strongly with the view that their institutional climate was hampered by destructive competition. Anderson and Swazey (1998) suggest that these findings might reflect a genuine disciplinary difference or could be the result of sociology students' greater awareness of social dimensions of organisations and higher expectations for social interaction. Similarly, students in psychology may through their choice of subject become more exposed to moral content and language than students in some other fields (Butterfield, Treviño and Weaver 2000), which could increase their sensitivity for ethical issues. In light of such findings, it is possible that the students in the behavioural sciences in our study had greater expectations for the supervisory relationship and were more attuned to recognising ethical issues in interpersonal relations and in the pedagogical relationship that a supervisory relationship represents.

\section{Methodological reflections}

It has been suggested that there is no substitute for on-site interviews when researching doctoral student experiences (Anderson and Swazey 1998). Also our experience is that the reflective and process-orientated research design with on-site interviews gave the participants the opportunity to reflect on various aspects of their supervision vis-à-vis their studies. Because of the distinctive features of the natural sciences versus the behavioural sciences (cf. McCune and Hounsell 2005; Lindblom-Ylänne, Trigwell, Nevgi, and 
Ashwin 2006) and the sample size, the study does not allow for generalisation of the results. Nevertheless, the semi-structured interviews allowed for identification of ethical issues embedded in a variety of formal and informal supervisory activities. We were able to apply to our data a rather universal theoretical conceptualisation (i.e. Kitchener 1985, 2000) suggesting that the results have transferability value.

Ethical issues in supervision were not an explicit interview topic, but pervaded many of the topics explored. Specific questions about the ethics of supervision may have produced different findings; however, exploring ethical dilemmas embedded in supervision enabled us to capture authentic manifestations of ethical problems in supervisory relationships without the 'social filters' that explicit questions about these sensitive issues may have activated in the participants.

Future research on the ethical problems experienced in doctoral supervision may benefit from a focus on problems in which a great discrepancy exists between the supervisor's and the student's views, i.e. one party does not recognise the issue or has very different experiences of it compared to the other party.

\section{References}

Alfredo, K., and H. Hart. 2011. The university and the responsible conduct of research: Who is responsible for what? Science and Engineering Ethics 17: 447-457.

Anderson, M. S., and K. S. Louis. 1994. The graduate student experience and subscription to the norms of science. Research in Higher Education 35: 273-299. 
Anderson, M. S., K. S. Louis, and J. Earle. 1994. Disciplinary and departmental effects on observations of faculty and graduate student misconduct. Journal of Higher Education 65: 331-350.

Anderson, M. S., and J. P. Swazey. 1998. Reflections on the graduate student experience: an overview. New Directions for Higher Education 101: 3-13.

Braun, V., and V. Clarke. 2006. Using thematic analysis in psychology. Qualitative Research in Psychology 3: 77-101.

Bruhn, J. G. 2008. Value dissonance and ethics failure in academia: A causal connection? Journal of Academic Ethics 6: 17-32.

Burr, V., and N. King. 2012. 'You're in Cruel England Now!' Teaching research ethics through reality television. Psychology Learning \& Teaching 11: 22-29.

Butterfield, K. D., L. K. Treviño, and G. T. Weaver. 2000. Moral awareness in business organizations: Influence of issue-related and social context factors. Human Relations, 53, 981-1018.

Case, J. 2008. Alienation and engagement: Development of an alternative theoretical framework for understanding student learning. Higher Education 55: 321-332.

Deuchar, R. 2008. Facilitator, director, or critical friend? : Contradiction and congruence in doctoral supervisory styles. Teaching in Higher Education 13: 489-500.

European Commission. 2007. Ethics for Researchers. Brussels. Accessed June 22, 2013 at ftp://ftp.cordis.europa.eu/pub/fp7/docs/ethics-for-researchers.pdf Finnish Advisory Board on Research Integrity. 2012. Responsible Conduct of Research and Procedures for Handling Allegations for Misconduct in Finland. Accessed June 22, 2013 at http://www.tenk.fi/sites/tenk.fi/files/HTK_ohje_2012.pdf

Gardner, S. 2007. "I heard it through the grapevine" Doctoral student socialization in 
chemistry and history. Higher Education 54: 723-740.

Gardner, S. K. 2009. Student and faculty attributions of attrition in high and low-completing doctoral programs in the United States. Higher Education 58: 97-112.

Gray, P. W., and S. R Jordan. 2012. Supervisors and academic integrity: supervisors as exemplars and mentors. Journal of Academic Ethics 10: 299-311.

Godecharle, S.,B. Nemery, and K. Dierickx. 2013. Guidance on research integrity: no union in Europe. Lancet 381, 1097-1098 + Appendix 6 p.

Golde, C. M. 2005. The role of the department and discipline in doctoral student attrition: Lessons from four departments. Journal of Higher Education 76: 669-700.

Golde, C. M., A. C. Bueschell, L. Jones, and G. E. Walker. 2009. Advocating apprenticeship and intellectual community: Lessons from the Carnegie Initiative on the Doctorate. In Doctoral education and the faculty of the future, ed. R. G. Ehrenberg and C. V. Kuh, 5364. Ithaca, NY: Cornell University Press.

Goodyear, R. K.,C. A. Crego, and M. W. Johnston. 1992. Ethical issues in the supervision of student research: A study of critical incidents. Professional Psychology: Research and Practice 23: 203-210.

Holmes, D. L., P. A. Rupert, S. A. Ross, and W. E. Shapera. 1999. Student perceptions of dual relationships between faculty and students. Ethics \& Behvaior, 9(2), 79-106.

Hyun, J., B. Quinn, T. Madon, and S. Lustig. 2007. Mental health need, awareness, and use of counseling services among international graduate students. Journal of the American College of Health 56: 109-118.

International Postgraduate Student Mirror. Catalonia, Finland, Ireland and Sweden. 2006. Swedish National Agency for Higher Education, 29R. 
Kitchener, K. S. 1985. Ethical principles and ethical decisions in student affairs. In New directions for student services: Applied ethics in student services, ed. H. J. Canon and R. D. Brown, 17-29. San Francisco: Jossey-Bass.

Kitchener, K. S. 2000. Foundations of ethical practice, research, and teaching in psychology. Lawrence Erlbaum.

Kurtz-Costes, B., A. L. Helmke, and B. Ülkü-Steiner. 2006. Gender and doctoral studies: The perceptions of PhD students in an American university. Gender \& Education 18: 137155.

Lee, A., and C. Williams. 1999. "Forged in fire". Narratives of trauma in PhD supervision pedagogy. Southern Review, 32(1), 6-26.

Lindblom-Ylänne, S., K. Trigwell, A. Nevgi, and P. Ashwin. 2006. How approaches to teaching are affected by discipline and teaching context. Studies in Higher Education 31: 285298.

Löfström, E., and K. Pyhältö. 2012. The supervisory relationship as an arena for ethical problem-solving. Education Research International, article ID 961505, 12 p. http://www.hindawi.com/journals/edu/2012/961505/

Löfström, E., and K. Pyhältö. 2014. Ethical issues in doctoral supervision - The perspectives of PhD students in the natural and behavioural sciences. Ethics \& Behavior 24: 195214.

Mahmud, S., and T. Bretag. 2013. Postgraduate research students and academic integrity: 'It's about good research training'. Journal of Higher Education Policy and Management, 35(4), 432-443.

Marshall, C., and G. B. Rossman. 1995. Designing Qualitative Research. London: Sage. 
McCune, V., and D. Hounsell. 2005. The development of students' way of thinking and practising in three final-year biology courses. Higher Education 49: 255-289.

Meyer, J. H. F., M. P. Shanahan, and R. C. Laugksch. 2005. Students' conceptions of research: A qualitative and quantitative analysis. Scandinavian Journal of Educational Research 49: $225-244$.

Murphy, N. W. 2004. Orientations to research higher degree supervision: The interrelatedness of beliefs about supervision, research, teaching and learning. (Doctoral dissertation). Griffith University, Brisbane. Accessed October 22, 2013 at https://www120.secure.griffith.edu.au/rch/file/526ad690-919a-3dc1-e20fe617b39ac839/1/02Whole.pdf

Pallas, A. M. 2001. Preparing education doctoral students for epistemological diversity. Educational Researcher 30: 6-11.

Protivnak, J. J., and L. L. Foss. 2009. An exploration of themes that influence the counselor education doctoral student experience. Counselor Education \& Supervision 48: 239256.

Pyhältö, K., J. Stubb, and K. Lonka. 2009. Developing scholarly communities as learning environments for doctoral students. International Journal for Academic Development 14: $221-232$.

Pyhältö, K., in collaboration with J. Stubb and J. Tuomainen. 2011. International evaluation of research and doctoral education at the University of Helsinki - To the top and out to society. Summary report on doctoral students' and principal investigators' doctoral training experiences. Accessed May 23, 2012 at http://wiki.helsinki.fi/display/evaluation2011/Survey+on+doctoral+training 
Pyhältö, K., J. Vekkaila, and J. Keskinen. 2012. Exploring the fit between doctoral students' and supervisors' perceptions of resources and challenges vis-à-vis the doctoral journey. International Journal of Doctoral Studies 7. Accessed February 20, 2014 at http://ijds.org/Volume7/IJDSv7p395-414Pyhalto383.pdf

Royal, K. D., J. V. Parrent, and R. P. Clark. 2011. Measuring education majors' percceptions of academic misconduct: an item response theory perspective. International Journal for Educational Integrity, 7(1), 18-29.

Stubb, J. 2012. Becoming a scholar. The dynamic interaction between the doctoral student and the scholarly community. Research Report 336. University of Helsinki, Faculty of Behavioural Sciences, Department of Teacher Education.

Sutherland, K. 2013. The 40-40-20 'myth' meets the 24/7 'reality': Investigating the experiences of early career academics. Keynote presentation at the Conference Higher Education - Higher Level Learning? Tallinn, Estonia, January 23-25, 2013.

Sweitzer, V. 2009. Towards a theory of doctoral student professional identity development: A developmental networks approach. Journal of Higher Education 80: 1-33.

True, G., L. B. Alexander, and K. A. Richman. 2011. Misbehaviors of front-line research personnel and the integrity of community-based research. Journal of Empirical Research on Human Research Ethics 6: 3-12.

Truong, K. 2010. Racism and racial trauma in doctoral study: How students of colour experience and negotiate the political complexities of racist encounters. A Doctoral Dissertation in Education. University of Pennsylvania.

Vekkaila, J., K. Pyhältö, K. Hakkarainen, J. Keskinen, and K. Lonka. 2013. Doctoral students' key learning experiences in the natural sciences. International Journal for Researcher Development 3: 154-183. 
Weidman, J. C., and E. L. Stein. 2003. Socialization of graduate students to academic norms. Research in Higher Education 44: 641-656.

Zucchero, R. A. 2008. Can psychology ethics be integrated into introductory psychology? Journal of Academic Ethics 6: 245-257. 